\title{
SIKAP DAN PERILAKU MEMBACA INFORMASI GIZI PADA LABEL PANGAN SERTA PEMILIHAN PANGAN KEMASAN
}

\author{
Qurrota A'yunil Huda', Dini Ririn Andrias' \\ ${ }^{1}$ Prodi S1 Ilmu Kesehatan Masyarakat, Minat Gizi Fakultas Kesehatan Masyarakat Universitas Airlangga \\ ${ }^{2}$ Departemen Gizi Kesehatan, Fakultas Kesehatan Masyarakat, Universitas Airlangga, Surabaya \\ Email: qurrotaayun.elhuda@gmail.com
}

\begin{abstract}
ABSTRAK
Pencegahan penyakit degeneratif dapat dilakukan dengan memperhatikan asupan makanan. Informasi gizi pada label pangan membantu seseorang dalam memilih makanan yang lebih sehat. Sikap terhadap informasi gizi dapat mempengaruhi perilaku seseorang dalam membaca label pangan dan pemilihan pangan kemasan. Membaca informasi gizi terbukti dapat meningkatkan konsumsi makanan sehat. Tujuan penelitian ini adalah menganalisis hubungan sikap, perilaku membaca informasi gizi, dan pemilihan pangan oleh mahasiswa. Penelitian cross sectional ini melibatkan 98 mahasiswa S1 angkatan 2013 Universitas Airlangga sebagai sampel penelitian. Responden diminta mengisi kuesioner berisi 5 poin sikap dan wawancara mengenai perilaku membaca informasi nilai gizi dan pemilihan pangan kemasan. Uji Chi square dan Pearson Chi square digunakan untuk menganalisis hubungan antara sikap, perilaku membaca informasi gizi dan pemilihan pangan. Mahasiswa yang memiliki sikap yang baik terkait kesehatan maupun informasi gizi pada label pangan tidak selalu mempraktikkan membaca informasi gizi dan memilih makanan dengan alasan kesehatan. Begitu juga label user tidak selalu memilih makanan dengan alasan kesehatan. Hasil penelitian menunjukkan tidak terdapat hubungan antara sikap, perilaku membaca informasi gizi dan pemilihan pangan $(\mathrm{p}>0,05)$. Diperlukan penelitian lebih lanjut untuk mengidentifikasi hambatan agar mahasiswa yang telah memiliki sikap yang baik dapat lebih membiasakan membaca informasi gizi dan memilih makanan yang sehat.
\end{abstract}

Kata kunci: informasi nilai gizi, membaca label pangan, pemilihan pangan, sikap

\section{ABSTRACT}

Practicing healthy food pattern can prevent from degenerative disease. Nutrition label, including nutrition facts on food label can help people choosing healthier food. Attitude toward nutrition label can influence nutrition label reading behavior and food choices, and reading food or nutrition label may influence healthier food consumption. This study was aimed to find association between attitude, nutrition label reading behavior and food choices among college students. This cross sectional study involved 98 undergraduate students class of 2013 Universitas Airlangga as the sample of the study. Respondents were made to answer 5 attitude points and asked about their nutrition label reading behavior and food choices. Chi square and Pearson Chi square were used to analyze association between attitudes, nutrition facts reading behavior, and food choices. Students who had good attitude about health and nutrition and nutrition label were not always became a label user or had healthy reason for food choices. Label users were not always had healthy reason for food choices. The study showed there was no association between attitudes and nutrition facts reading behavior, as well as between attitude and food choices ( $p>0,05)$. Further study to identify barriers of reading food and nutrition label behavior need to be conducted.

Keywords: attitude, food choice, food label, nutrition label

\section{PENDAHULUAN}

Penyakit degeneratif mulai cenderung meningkat pada usia $\geq 15$ tahun dan $\geq 18$ tahun di setiap provinsi di Indonesia (Balitbangkes, 2013). Salah satu pencegahan yang dapat dilakukan adalah dengan mengonsumsi beragam makanan dan memperhatikan kecukupan zat gizi agar tidak kurang atau pun berlebih. Pola konsumsi yang baik perlu dibentuk seawal mungkin karena kebiasaan makan sejak kecil akan menjadi awal proses pembentukan pola makan pada usia dewasa dan berpengaruh pada kondisi kesehatan jangka panjang (Larson, dkk., 2008).

Informasi gizi pada kemasan pangan yang memuat gambaran isi dan kandungan gizi dari pangan tersebut merupakan informasi yang dapat 
dimanfaatkan oleh konsumen untuk memilih pangan kemasan yang sehat (UU no. 18 tahun 2014). Membiasakan membaca label khususnya informasi nilai gizi yang tertera pada kemasan pangan perlu dilakukan untuk memudahkan konsumen memilih makanan sesuai kebutuhannya, terutama terkait makanan dengan kandungan yang perlu dibatasi seperti gula, garam, dan lemak (Kemenkes, 2014). Orang yang paham mengenai gizi, mementingkan gizi dibandingkan dengan rasa ketika membeli makanan, dan percaya terdapat hubungan antara asupan makanan dengan kondisi kesehatan, lebih mungkin untuk membaca informasi nilai gizi pada label pangan (Guthrie, dkk., 1995).

Sikap menentukan motivasi seseorang untuk mengimplementasikan perilaku tertentu. Contohnya yaitu ketika memilih makanan, gizi hanya menjadi salah satu hal yang diperhitungkan bersamaan dengan rasa, harga, dan kemudahan. Apabila konsumen tidak menilai gizi sebagai faktor yang penting untuk memilih makanan atau bila konsumen merasa faktor lain lebih penting, konsumen kemungkinan akan memilih makanan yang tidak bergizi meskipun mengerti mengenai gizi (Guthrie, dkk., 1999). Orang yang melihat informasi gizi karena paham dan memperhatikan asupan gizi tubuhnya, terbukti cenderung memilih makanan yang lebih sehat. Penelitian menunjukkan bahwa orang tua yang perlu menjaga diet (Gough dan Conner, 2006), orang yang terbiasa mengonsumsi makanan rendah lemak (Neuhouser, 1999), orang obesitas dan terbiasa banyak mengonsumsi buah dan sayur (Satia, dkk., 2005) lebih memilih makanan yang sehat.

Informasi gizi pada label pangan menjadi salah satu sumber informasi untuk mengetahui apakah makanan tersebut sehat (Biloukha dan Utermohlen, 2001; Story, dkk., 2002). Penelitian menunjukkan bahwa konsumsi kolesterol dan lemak berkurang pada orang yang membaca informasi gizi pada label pangan (Guthrie, dkk., 1995). Hal tersebut diperkuat oleh penelitian Burton, dkk. (2009) yang menunjukkan adanya perubahan pilihan makanan setelah seseorang melihat kandungan gizi dari makanan tertentu. Penelitian ini bertujuan menganalisis hubungan antara sikap dan perilaku membaca informasi nilai gizi pada label pangan serta pemilihan pangan kemasan pada mahasiswa yang mewakili kelompok usia dewasa muda.

\section{METODE}

Penelitian cross sectional ini dilakukan di Surabaya dengan melibatkan mahasiswa S1 reguler angkatan 2013 Universitas Airlangga sebagai sampelnya. Dua program studi yang masing-masing mewakili bidang kesehatan dan non kesehatan dipilih secara acak. Besar sampel adalah 98 mahasiswa dari kedua program studi tersebut yang dipilih secara acak.

Responden diminta untuk mengisi kuesioner mengenai sikap terkait kesehatan ( 2 pernyataan) dan informasi gizi (3 pernyataan) dengan memilih skala $1-7$ dimana skala 1 berarti sangat tidak setuju dengan pernyataan, skala 7 berarti sangat setuju dengan pernyataan, dan skala 4 berarti netral (Smith, dkk., 1999). Analisis pada sikap dilakukan dengan menjumlahkan skor kemudian dikategorikan menjadi 2, yaitu $\geq$ median dan $<$ median. Median skor sikap terkait kesehatan adalah 8 , sedangkan median skor sikap terkait informasi nilai gizi adalah 12 .

Perilaku responden terkait kebiasaan membaca label gizi dilihat dari jawaban responden mengenai frekuensi membaca informasi nilai gizi. Jawaban 'tidak pernah' atau 'jarang' dikategorikan sebagai non label user. Jawaban 'sering' atau 'selalu' dikategorikan sebagai label user (Smith, dkk., 1999).

Pemilihan pangan dilihat dari berapa jumlah makanan yang dipilih responden dengan alasan yang berkaitan dengan kesehatan. Responden ditunjukkan 9 kemasan pangan yang terdiri dari 3 macam minuman, 3 macam snack, dan 3 macam yogurt. Merk dan nama dagang pada kemasan disamarkan dan kemudian diganti dengan kode I, II, dan III untuk masing-masing jenis makanan. Kemudian responden diminta untuk memilih salah satu dari masing-masing jenis makanan dan memberikan alasan memilih produk tersebut. Alasan kemudian dikelompokkan menjadi alasan kesehatan jika alasan yang dikemukakan responden adalah produk tersebut mengandung kalsium yang lebih banyak atau karena responden sedang menjaga berat badan tubuh sehingga memilih 
Tabel 2. Hubungan antara Sikap dan Perilaku Mahasiswa dalam Membaca Informasi Nilai Gizi

\begin{tabular}{|c|c|c|c|c|c|c|c|}
\hline \multirow{3}{*}{ Sikap } & \multicolumn{4}{|c|}{ Perilaku } & \multirow{2}{*}{\multicolumn{2}{|c|}{ Total }} & \multirow{3}{*}{$P-$ value* } \\
\hline & \multicolumn{2}{|c|}{ Label user } & \multicolumn{2}{|c|}{ Non label user } & & & \\
\hline & $\mathbf{n}$ & $\%$ & n & $\%$ & n & $\%$ & \\
\hline \multicolumn{8}{|l|}{ Sikap terhadap Kesehatan } \\
\hline Skor sikap $\geq$ median $(\geq 8)$ & 44 & 45,8 & 52 & 54,2 & 96 & 98,0 & 0,422 \\
\hline Skor sikap < median $(<8)$ & 2 & 100,0 & 0 & 0 & 2 & 2,0 & \\
\hline \multicolumn{8}{|l|}{ Sikap terhadap Pelabelan } \\
\hline Skor sikap $\geq$ median $(\geq 12)$ & 41 & 47,7 & 45 & 52,3 & 86 & 87,8 & 0,935 \\
\hline Skor sikap $<$ median $(<12)$ & 5 & 41,7 & 7 & 58,3 & 12 & 12,3 & \\
\hline
\end{tabular}

*Uji Chi square: signifikan jika $\mathrm{p}<0,05$

produk dengan kalori dan lemak yang lebih rendah. Uji Chi square digunakan untuk menganalisis hubungan antara sikap dengan perilaku membaca informasi gizi dan uji Pearson chi square digunakan untuk melihat hubungan antara sikap dengan pemilihan pangan dan perilaku membaca informasi gizi dengan pemilihan pangan.

\section{HASIL DAN PEMBAHASAN}

Tabel 1. Sikap Responden Terkait Kesehatan dan Sikap Terkait Pelabelan Makanan

\begin{tabular}{lcc}
\hline \multicolumn{1}{c}{ Sikap } & n & \% \\
\hline \multicolumn{2}{l}{ Sikap Terkait Kesehatan } & \\
\hline \multicolumn{2}{l}{ Makanan berpengaruh pada kondisi kesehatan } \\
TS/STS & 1 & 1,0 \\
Netral & 5 & 5,1 \\
S/SS & 92 & 93,9 \\
\hline Perlu membatasi asupan tertentu & & \\
TS/STS & 3 & 3,0 \\
Netral & 7 & 7,1 \\
S/SS & 88 & 89,9 \\
\hline Sikap Terkait Pelabelan & & \\
\hline Pentingnya membaca informasi gizi & & \\
TS/STS & 6 & 6,1 \\
Netral & 12 & 12,2 \\
S/SS & 80 & 81,7 \\
\hline Kebenaran informasi nilai gizi & & \\
TY/STY & 16 & 16,4 \\
Netral & 34 & 34,7 \\
Y/SY & 48 & 49,9 \\
\hline Kebenaran klaim & & \\
TY/STY & 30 & 30,5 \\
Netral & 29 & 29,6 \\
Y/SY & 39 & 39,9 \\
\hline S-Setuju & & \\
\hline
\end{tabular}

* $\mathrm{S}=$ Setuju; $\mathrm{SS}=$ Sangat Setuju; TS=Tidak Setuju; STS=Sangat Tidak Setuju; Y=Yakin; TY=Tidak Yakin; STY=Sangat Tidak Yakin
Sebagian besar mahasiswa setuju bahwa asupan makanan akan mempengaruhi kondisi kesehatan (93,9\%). Sebagian besar juga setuju perlunya membatasi konsumsi gula, garam, dan lemak untuk menghindari masalah kesehatan tertentu $(89,9 \%)$.

Sebanyak $81,7 \%$ mahasiswa merasa bahwa memperhatikan label gizi penting dilakukan untuk mendapatkan makanan yang sehat. Sebanyak $34,7 \%$ mahasiswa netral atau tidak bisa menentukan untuk percaya atau tidak terhadap infomasi pada label pangan, dan sebesar 30\% ragu akan kebenaran klaim gizi/ kesehatan pada label.

Mayoritas responden setuju bahwa asupan makanan berpengaruh pada kondisi kesehatan dan bahwa perlu untuk mengurangi konsumsi gula, garam, dan lemak. Hal ini sesuai dengan penelitian oleh Pawlak dan Colbi (2009) dan Smith, dkk. (1999).

Tabel 2 menunjukkan mayoritas responden (98\%) setuju bahwa asupan makanan berpengaruh pada kondisi kesehatan dan bahwa perlu untuk mengurangi konsumsi gula, garam, dan lemak. Namun hal ini tidak menjadikan mereka sering atau selalu membaca informasi nilai gizi yang memberikan informasi mengenai persentase kandungan zat gizi pada produk pangan kemasan karena $54,2 \%$ di antaranya adalah non label user. Jumlah responden yang menunjukkan bahwa mahasiswa memiliki sikap yang baik terkait informasi nilai gizi pada label pangan lebih sedikit jika dibandingkan dengan sikap pada kesehatan $(87,8 \%)$, namun masih menunjukkan bahwa mayoritas responden memiliki sikap yang baik. Jumlah responden yang memiliki sikap yang baik 
Tabel 3. Hubungan antara Sikap dan Pemilihan Pangan Kemasan

\begin{tabular}{|c|c|c|c|c|c|c|c|c|c|c|c|}
\hline \multirow{3}{*}{ Sikap } & \multicolumn{8}{|c|}{ Pemilihan Pangan } & \multirow{2}{*}{\multicolumn{2}{|c|}{ Total }} & \multirow{3}{*}{$P$-value* } \\
\hline & \multicolumn{2}{|c|}{$\begin{array}{c}\text { Memilih 1 } \\
\text { makanan } \\
\text { dengan alasan } \\
\text { kesehatan } \\
\end{array}$} & \multicolumn{2}{|c|}{$\begin{array}{c}\text { Memilih 2 } \\
\text { makanan } \\
\text { dengan alasan } \\
\text { kesehatan }\end{array}$} & \multicolumn{2}{|c|}{$\begin{array}{c}\text { Memilih } 3 \\
\text { makanan } \\
\text { dengan alasan } \\
\text { kesehatan }\end{array}$} & \multicolumn{2}{|c|}{$\begin{array}{c}\text { Memilih 0 } \\
\text { makanan } \\
\text { dengan alasan } \\
\text { kesehatan }\end{array}$} & & & \\
\hline & $\mathbf{n}$ & $\%$ & $\mathbf{n}$ & $\%$ & $\mathbf{n}$ & $\%$ & $\mathbf{n}$ & $\%$ & $\mathrm{n}$ & $\%$ & \\
\hline \multicolumn{12}{|l|}{ Sikap Terhadap Kesehatan } \\
\hline Skor sikap $\geq$ median $(\geq 8)$ & 23 & 24,0 & 14 & 14,6 & 17 & 17,7 & 42 & 43,8 & 96 & 100,0 & 0,593 \\
\hline Skor sikap $<$ median $(<8)$ & 0 & 0 & 0 & 0 & 1 & 50,0 & 1 & 50,0 & 2 & 100 & \\
\hline \multicolumn{12}{|l|}{ Sikap Terhadap Pelabelan } \\
\hline Skor sikap $\geq$ median $(\geq 12)$ & 22 & 26,7 & 10 & 11,6 & 17 & 19,8 & 37 & 43,2 & 86 & 100,0 & 0,565 \\
\hline Skor sikap $<$ median $(<12)$ & 1 & 8,3 & 4 & 33,3 & 1 & 8,3 & 6 & 50,0 & 12 & 100 & \\
\hline
\end{tabular}

*Uji Pearson Chi square: signifikan jika $<<0,05$

tetapi tidak mempraktikkan perilaku membaca informasi gizi adalah sebanyak 52,3\%. Uji Chi square menunjukkan tidak terdapat hubungan antara sikap dengan perilaku membaca informasi gizi karena $\mathrm{p}>0,05$.

Penelitian lain menyebutkan bahwa rasa percaya seseorang pada pengaruh diet rendah lemak dan tinggi serat pada kejadian kanker menunjukkan hubungan dengan perilaku membaca informasi nilai gizi. Namun, terlepas dari seharusnya informasi gizi pada label pangan dapat dimanfaatkan untuk mengetahui kandungan gizi pada produk pangan, pada penelitian ini hasil menunjukkan tidak adanya hubungan. Responden cenderung setuju pada pentingnya pencantuman informasi gizi dan percaya pada informasi nilai gizi dan klaim yang dicantumkan pada label pangan, akan tetapi jumlah yang menjadi label user tidak terlalu berbeda jauh dari yang menjadi non label user.

Tabel 3 menunjukkan mayoritas responden yang memiliki skor sikap terkait kesehatan di atas median lebih banyak yang memilih makanan bukan karena alasan kesehatan $(43,8 \%)$. Begitu juga pada sikap terkait informasi gizi pada label pangan. Mayoritas responden yang memiliki skor sikap terkait informasi gizi di atas median lebih banyak yang memilih makanan bukan dengan alasan kesehatan (43,0\%). Uji Pearson Chi square menunjukkan tidak terdapat hubungan antara sikap dengan pemilihan pangan kemasan $(\mathrm{p}>0,05)$.

Meskipun responden setuju bahwa informasi gizi penting untuk dicantumkan pada kemasan pangan agar mendapatkan makanan yang sehat, namun tidak menjamin responden akan membaca label sebelum membeli. Apabila seseorang belum memiliki masalah kesehatan, fokus pada kondisi kesehatan tertentu, tidak memiliki ketertarikan pada gizi, dan tidak memiliki rencana diet tertentu, seseorang lebih dimungkinkan tidak membaca informasi gizi pada label pangan (Thedford, 2005; Rothman, dkk., 2006; Auchincloss, dkk., 2013; Lin, dkk., 2004). Orang yang biasanya mengonsumsi makanan rendah lemak akan menggunakan label untuk mengetahui lemak yang terkandung pada produk (Neuhouser, 1999). Orang dengan status gizi obesitas dan yang biasa mengonsumsi buah dan sayuran lebih banyak yang membaca informasi gizi pada label pangan (Satia, dkk., 2005). Meskipun membaca informasi gizi, seseorang masih mungkin memilih makan tanpa mempertimbangkan informasi pada label yang dibaca, seperti harga dari makanan menjadi pendorong yang lebih kuat dibandingkan kandungan gizi (Auchincloss, dkk., 2013). Pada hasil gambaran sikap menunjukkan bahwa responden cenderung kesulitan menentukan untuk percaya atau tidak pada informasi nilai gizi dan klaim pada label pangan. Pendapat bahwa makanan yang sehat tidak hanya ditentukan dari apa yang tercantum pada label pangan dan kurang percaya pada kebenaran konten informasi gizi pada label pangan dapat menjadikan seseorang merasa tidak perlu membaca informasi tersebut (Campos, dkk., 2011; Cowburn dan Stockley, 2004; Auchincloss, dkk., 2013).

Uji Pearson Chi square menunjukkan tidak terdapat hubungan antara perilaku membaca 
Tabel 4. Hubungan antara Perilaku Membaca Informasi Gizi dan Pemilihan Pangan

\begin{tabular}{|c|c|c|c|c|c|c|c|c|c|c|c|}
\hline \multirow{3}{*}{ Perilaku } & \multicolumn{8}{|c|}{ Pemilihan Pangan } & & & \multirow{3}{*}{$P$-value* } \\
\hline & \multicolumn{2}{|c|}{$\begin{array}{c}\text { Memilih } 1 \\
\text { makanan dengan } \\
\text { alasan kesehatan }\end{array}$} & \multicolumn{2}{|c|}{$\begin{array}{c}\text { Memilih 2 } \\
\text { makanan } \\
\text { dengan alasan } \\
\text { kesehatan }\end{array}$} & \multicolumn{2}{|c|}{$\begin{array}{c}\text { Memilih } 3 \\
\text { makanan } \\
\text { dengan alasan } \\
\text { kesehatan }\end{array}$} & \multicolumn{2}{|c|}{$\begin{array}{c}\text { Memilih 0 } \\
\text { makanan } \\
\text { dengan alasan } \\
\text { kesehatan }\end{array}$} & \multicolumn{2}{|c|}{ Total } & \\
\hline & $\mathrm{n}$ & $\%$ & $\mathbf{n}$ & $\%$ & $\mathrm{n}$ & $\%$ & $\mathbf{n}$ & $\%$ & n & $\%$ & \\
\hline Label user & 19 & 41,3 & 11 & 23,9 & 7 & 15,2 & 9 & 19,6 & 46 & 100 & 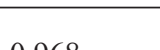 \\
\hline Non label user & 24 & 46,15 & 12 & 23,1 & 7 & 13,5 & 9 & 17,3 & 52 & 100 & 0,968 \\
\hline
\end{tabular}

*Uji Pearson Chi square: signifikan jika $\mathrm{p}<0,05$

informasi gizi dengan pemilihan pangan ( $p>0,05)$. Responden label user yang memilih 3 makanan dengan alasan kesehatan sebanyak $15,2 \%$ sedangkan dari responden non label user sebanyak $13,5 \%$. Sebanyak $19,6 \%$ responden label user dan 17,3\% non label user memilih makanan bukan dengan alasan kesehatan. Sikap yang baik tidak menjadikan responden lebih memilih dengan alasan kesehatan. Alasan yang diutarakan responden antara lain responden lebih memilih makanan yang familiar atau sering ditemui di toko dan lebih mudah untuk dicari. Beberapa alasan tersebut dapat menjadikan responden lebih memilih bukan karena alasan kesehatan (Sun, 2008; Pawlak dan Colby, 2009).

Alasan lain seperti karena rasa makanan kurang enak seperti misalnya snack dan minuman yang banyak mengandung serat dan mengandung buah, minuman yang memiliki rasa kacang hijau yang kuat, atau karena tekstur dari makanan tersebut kurang menyenangkan, dapat dijadikan alasan tidak memilih makanan yang sehat (Gough dan Conner, 2006; Stevenson, dkk., 2007; Biloukha dan Utermohlen, 2001).

Secara umum, hasil penelitian menunjukkan bahwa responden lebih banyak yang memilih makanan bukan dengan alasan kesehatan. Penghalang seseorang dalam mempraktikkan pemilihan makanan yang sehat dapat terjadi karena kurangnya kepedulian pada kondisi kesehatan jangka panjang (Frank, 1998; Smith, dkk., 1999; Larson, dkk., 2008). Responden masih fokus pada kondisi kesehatan saat ini sehingga apabila dirasa saat ini masih dalam keadaan sehat, belum perlu untuk memperhatikan apa yang dikonsumsi meskipun responden setuju bahwa apa yang dikonsumsi berpengaruh pada kondisi kesehatan
(Gough dan Conner, 2006). Anggapan bahwa memperhatikan diet hanya perlu dilakukan oleh orang yang memiliki penyakit tertentu dan orang tua, atau bagi orang yang gemuk sehingga perlu menguruskan badan juga merupakan penghalang dalam memilih makanan sehat (Gough dan Conner, 2006; Stevenson, dkk., 2007). Pada hasil skor sikap menunjukkan bahwa responden cenderung kesulitan menentukan untuk percaya atau tidak pada informasi nilai gizi dan klaim pada label pangan. Rasa ragu pada kebenaran informasi nilai gizi dan klaim dapat menjadi penghalang atau barrier dalam memanfaatkan informasi nilai gizi (Shepherd dan Raats, 2008).

Rasa ragu-ragu dapat muncul karena responden mendapatkan informasi mengenai gizi selain dari label pangan seperti dari saudara, teman, kenalan, profesional, iklan, leaflet, atau buku (Biloukha dan Utermohlen, 2001; Story, dkk., 2002). Apabila iklan lebih banyak menunjukkan produk makanan yang kurang sehat bisa menjadi pendorong untuk mengonsumsi makanan yang kurang sehat atau karena tren makanan adalah makanan kurang sehat juga dapat menjadi penyebab (Harrison dan Marske, 2005; (Stead, dkk., 2011). Pengaruh kelompok juga dapat berperan semisal apabila kelompok cenderung mengonsumsi makanan yang sehat, anggota kelompok tersebut akan lebih besar kemungkinan untuk mengonsumsi makanan yang sehat pula (Auchincloss, dkk., 2013).

\section{KESIMPULAN DAN SARAN}

Lebih banyak mahasiswa yang menjadi non label user (jarang atau tidak pernah membaca informasi gizi) dibandingkan dengan mahasiswa yang menjadi label user (sering atau selalu 
membaca label gizi). Kebanyakan mahasiswa memilih makanan bukan karena memperhatikan masalah kesehatan tertentu atau kandungan gizi yang terkandung dalam makanan. Tidak terdapat hubungan antara sikap, perilaku membaca informasi gizi, dan pemilihan pangan.

Mahasiswa yang telah memiliki sikap yang baik perlu meningkatkan kebiasaan membaca informasi gizi dan memilih makanan yang sehat. Penelitian lebih lanjut perlu dilakukan untuk mengetahui hambatan mahasiswa dalam mempraktikkan perilaku membaca informasi gizi dan memilih makanan dengan alasan terkait kesehatan.

\section{DAFTAR PUSTAKA}

Auchincloss A.H., Young C., Davis A.L., Wasson S., Chilton M., Karamanian V. (2013). Barriers and facilitators of consum er use of nutrition labels at sit-down restaurant chains. Public Health Nutrition, 16(12), 2138-2145.

Biloukha OO \& Utermohlen V. (2001). Healthy eating in Ukraine: attitudes, barriers, and information source. Public Health Nutrition, 4(2), 207.

Badan Penelitian dan Pengembangan Kesehatan. 2013. Riset Kesehatan Dasar 2013. Jakarta: Kementrian Kesehatan RI.

Burton,S., Howlett, E., Tangar, A. H. (2009). Food for thought: how will the nutrition labeling of quick service restaurant menu items influence consumers' product evaluations, purchase intentions, and choices?. Journal of Retailing, 85(3), 258-273. Diakses dari http:// www.sciencedirect.com/science/article/pii/ S0022435909000232

Campos S, Doxey J, Hammand. (2011). Nutrition labels on pre-packaged foods: A systematic review. Public Health Nutrition, 14(8), 1496-1506

Cowburn G \& Stockley L. (2004). Consumer understanding and use of nutrition labelling: a systematic review. Public Health Nutrition, 8, 21-28.

Frank G. (1998). Nutrition for teens. Dalam Henderson, dkk. 1988. Promoting teen health: linking schools, health organization, and community. USA: Sage Publication.

Gough, B. dan Conner,M.T. (2006). Barriers to healthy eating amongst men: A qualitative analysis. Social Science \& Medicine, 62, 387-395.
Guthrie, JF, Derby, BM, Levy AS. (1999). What people know and do not know about nutrition. Dalam American's eating habits: Changes and consequences. $243-290$.

Guthrie JF, Fox JJ, Cleveland LE, Welsh S. (1995). Who uses nutrition labeling, and what effects does label use have on diet quality?. Journal of Nutrition Education, 27, 163 - 172.

Harrison K \& Marske AL. (2005). Nutrition content of foods ad during the television program children watch most American. Journal of Public Health, 95, 1568 - 1574.

Kementrian Kesehatan RI. (2014). Pedoman gizi seimbang. Jakarta: Dirjen Bina Gizi dan KIA

Larson NI, Fulkerson JA, Stang J. (2008). Adolescence. Dalam Thomson dan Ward. 2008. Optimizing woman's health through nutrition. USA: CRC Press taylor and Francis Group.

Lin CJ, Lee JY, Yen ST. (2004). Do dietary intakes affect search for nutrient information on food label. Elsevier, 59, 1955-1967.

Neuhouser ML. (1999). Use of food nutrition labels is associated with lower fat intake. Journal of The American Diet Association, 99, 45-53.

Pawlak R \& Colby S. (2009). Benefits, barriers, self-efficacy and knowledge regarding healthy foods; perception of African Americans living in eastern North Carolina. Diakses pada 7 Februari 2016http://synapse.koreamed.org/ViewImage. php Type $=$ T\&aid $=460716 \&$ id $=$ T $5 \&$ afn $=16$ 1 NRP $3156 \& \mathrm{fn}=0161 \mathrm{NRP}$.

Rothman RL, Housam R, Weiss H, Davis D. (2006). Patient understanding of food lables: The role of literacy and numeracy. American Journal of Preventive Medicine Elsevier, 391 - 398.

Satia JA, Galanko JA, Neuhouser ML. (2005). Food nutrition label use is associated with demographic, behavioral and psychosocial factors and dietary intake among African Americans in North Carolina. $J$ Am Diet Assoc, 105(3), 392-402. doi: 10.1016/j. jada.2004.12.006

Shepherd R. \& Raats M., (2006). The psychology of food choice. UK: Biddles Ltd.

Smith SC, Taylor JG \& Alison, SM. (1999). Use of food labels and beliefs about diet-disease relationships among university students. Public Health Nutrition, 3(2), 175 - 182.

Stead M, McDemott L, MacKintosh AM, Adamson A. (2011). Why healthy eating is bad for young people's health: healthy, belonging, and food. Elsevier, 72, 1131 - 1139 . 
Stevenson C, Doherty G, Barnett J, Muldoon OT, Trew K. (2007). Adolescents view of food and eating: Identifying barriers to healthy eating. Journal of Adolescense, 30, 417 - 434.

Story SJ, Neumark, French. (2002). Individual and environmental influences on adolescent eating behavior. Journal of the American Dietetic Association, 10, 40 - 51.
Sun, YHC. (2007). Health concern, food choid motives, and attitudes toward healthy eating: The mediating role of food choice motives. Elsevier, 51, 42-49.

Thedford, K. (2005). Food label: Who being educated. American Dietetic Association, 105, 402 - 403.

UU RI Tahun 2012 No 18 Tentang Pangan. 